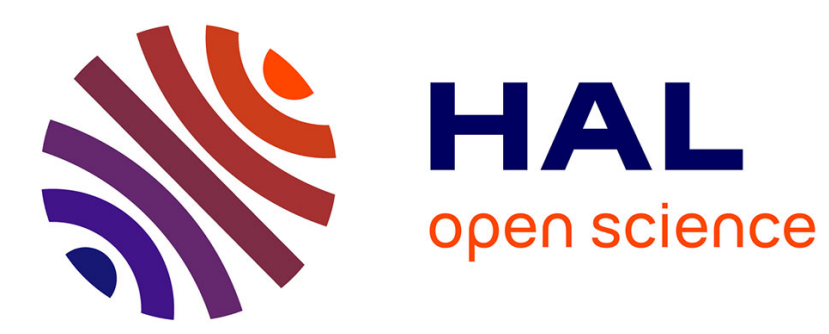

\title{
Generalization of the polymorphism with 2D fluid smectic phases
}

\author{
G. Sigaud, M.F. Achard, F. Hardouin
}

\section{To cite this version:}

G. Sigaud, M.F. Achard, F. Hardouin. Generalization of the polymorphism with 2D fluid smectic phases. Journal de Physique Lettres, 1985, 46 (17), pp.825-830. 10.1051/jphyslet:019850046017082500 . jpa-00232905

\section{HAL Id: jpa-00232905 https://hal.science/jpa-00232905}

Submitted on 1 Jan 1985

HAL is a multi-disciplinary open access archive for the deposit and dissemination of scientific research documents, whether they are published or not. The documents may come from teaching and research institutions in France or abroad, or from public or private research centers.
L'archive ouverte pluridisciplinaire HAL, est destinée au dépôt et à la diffusion de documents scientifiques de niveau recherche, publiés ou non, émanant des établissements d'enseignement et de recherche français ou étrangers, des laboratoires publics ou privés. 
Classification

Physics Abstracts

$61.30 \mathrm{~J}-64.70 \mathrm{E}$

\title{
Generalization of the polymorphism with 2D fluid smectic phases
}

\author{
G. Sigaud, M. F. Achard and F. Hardouin \\ Centre de Recherche Paul Pascal, Université de Bordeaux I, 33405 Talence Cedex, France
}

(Reçu le 15 mai 1985, accepté le 5 juillet 1985)

\begin{abstract}
Résumé. - A partir d'observations microscopiques sur gouttes libres nous avons localisé différentes lignes de transition entre phases smectiques fluides bidimensionnelles dans des diagrammes binaires concentration-température. Nous avons en particulier défini un critère de changement de texture pour identifier la transition $S_{\widetilde{\mathbf{C}}}-S_{\widetilde{\mathbf{A}}}$. Nous concluons à l'ordre de succession des phases $S_{\widetilde{\mathbf{C}}^{-}} \mathbf{S}_{\tilde{\mathbf{A}}^{-}}-\mathbf{S}_{\mathbf{A}_{\text {cre }}}$ par abaissement de la température.
\end{abstract}

\begin{abstract}
On the basis of microscopic observations on free droplets we have located different transition lines between 2D fluid smectic phases in $(x, T)$ binary diagrams. In particular a textural criterion has been defined to identify for the first time the $\mathbf{S}_{\tilde{\mathbf{C}}}-S_{\tilde{\mathbf{A}}}$ phase transition. Our studies lead to the classification of three $2 \mathrm{D}$ fluid smectics according to the following sequence : $\mathrm{S}_{\tilde{\mathrm{C}}}-\mathrm{S}_{\tilde{\mathrm{A}}}-\mathrm{S}_{\mathrm{A}_{\text {cre }}}$ with decreasing temperature.
\end{abstract}

All smectic A phases are uniaxial mesophases which are constituted of unstructured layers. Referring to some polar systems (pure compounds or binary mixtures) three kinds of $S_{A}-S_{A}$ transitions were discovered these last few years : monolayer smectic $\mathrm{A}\left(\mathrm{S}_{\mathrm{A}_{1}}\right) \stackrel{T \backslash}{\longrightarrow}$ bilayer smectic $\mathrm{A}$ $\left(\mathrm{S}_{\mathrm{A}_{2}}\right)$, partially bilayer smectic $\mathrm{A}\left(\mathrm{S}_{\mathrm{A}_{\mathrm{d}}}\right) \stackrel{T \rtimes}{\longrightarrow}$ bilayer smectic $\mathrm{A}\left(\mathrm{S}_{\mathrm{A}_{2}}\right)$, partially bilayer smectic $\mathrm{A}$ $\left(\mathrm{S}_{\mathrm{A}_{\mathrm{d}}}\right) \stackrel{T \searrow}{\longrightarrow}$ monolayer smectic $\mathrm{A}\left(\mathrm{S}_{\mathrm{A}_{1}}\right)$ changes.

In addition to these direct $S_{A}-S_{A}$ phase transitions and to the multireentrant $\mathrm{NS}_{A}$ phenomena, intermediate states can occur between two types of smectic A phases [1,2]. These new mesophases possess a two-dimensional (2D) arrangement due to a long range modulation in the plane of the layers. Nevertheless, in terms of local order they remain smectic with liquid like ordered layers (i.e. fluid smectics).

Indeed, cooling from a monolayer smectic phase $\left(\mathrm{S}_{\mathrm{A}_{1}}\right)$ or a partial bilayer smectic $\mathrm{A}$ phase $\left(\mathrm{S}_{\mathbf{A}_{\mathrm{d}}}\right)$, it is possible to find a $2 \mathrm{D}$ oblique lattice (ribbon phase or tilted fluid antiphase $\mathrm{S}_{\tilde{\mathbf{C}}}$ ) before the condensation of the bilayer smectic A phase $\left(\mathrm{S}_{\mathrm{A}_{2}}\right)[3,4]$.

Sometimes the $S_{A_{1}}-S_{A_{2}}$ change requires a second intermediate phase with a $2 D$ centred rectangular lattice ( fluid antiphase $\mathrm{S}_{\tilde{\mathrm{A}}}$ ) [5]. This sequence can be even more complex with the appearance of a third additional phase (crenelated $S_{A}$ phase : $S_{A_{c r e}}$ ) between the $S_{\tilde{A}}$ phase and the $S_{A_{2}}$ phase. A. M. Levelut [6] has shown that the $S_{A_{\text {cre }}}$ has a $2 \mathrm{D}$ simple rectangular lattice.

In fact, at short range order the $S_{\tilde{\mathbf{C}}}, S_{\tilde{\mathbf{A}}}, S_{\mathbf{A}_{\text {crie }}}$ phases are very close to the bilayer smectic arrangement, but these structures are broken periodically by defect walls. 
On the basis of microscopic observations on free droplets we have located different transition lines in (molar fraction $x$, temperature $T$ ) binary diagrams.

A thin droplet of a given sample is deposited on a glass slide and its free surface is observed between crossed polarizer and analyser $(\times 400)$ in an homeotropic configuration.

These microscopic observations are made in the temperature range of the $(x, T)$ binary diagrams where the fluid mesophases exist.

\section{$\mathbf{S}_{\mathrm{A}_{1}}-\mathbf{S}_{\tilde{A}}-\mathbf{S}_{\mathrm{A}_{\text {cre }}}-\mathbf{S}_{\mathrm{A}_{2}}$ sequence}

By mixing 4-(pentylphenylbenzoyloxy)-4-cyanobenzoate (DB5) with 4-cyanobenzoyloxy-4'pentylstilbene (C5 stilbene) (see formulae in Table I) the first example of a $S_{A_{1}}-S_{\tilde{A}^{-}}-S_{A_{2}}$ sequence was found [5]. In this original paper we pointed out that the $S_{A_{1}}-S_{\widetilde{A}}$ transition involved characteristic lines of defects which develop and strengthen with decreasing temperature. Then the $S_{\tilde{\mathbf{A}}}-\mathrm{S}_{\mathrm{A}_{2}}$ change occurred through what appeared (at this time) to be a transient texture, made of small domains which join together and finally disappear in $S_{A_{2}}$ phase. In fact recent results [7] have shown that this new evolving texture is connected to an additional $\mathrm{S}_{\mathbf{A}_{\text {cre }}}$ phase.

Table I.

\begin{tabular}{l|c}
\hline Acronym & Formula \\
\hline $\mathrm{DB} 5$ & $\mathrm{C}_{5} \mathrm{H}_{11}-\mathrm{O}-\mathrm{OCO}-\mathrm{O}-\mathrm{OCO}-\mathrm{O}-\mathrm{CN}$ \\
\hline $\mathrm{C} 5$ stilbene & $\mathrm{C}_{5} \mathrm{H}_{11}-\mathrm{O}-\mathrm{CH}=\mathrm{CH}-\mathrm{O}-\mathrm{OOC}-\mathrm{O}-\mathrm{CN}$ \\
\hline $\mathrm{DB} 7 \mathrm{NO}_{2}$ & $\mathrm{C}_{7} \mathrm{H}_{15}-\mathrm{O}-\mathrm{OCO}-\mathrm{O}-\mathrm{OCO}-\mathrm{O}-\mathrm{NO}_{2}$ \\
\hline $\mathrm{DB} 8 \mathrm{NO}_{2}$ & $\mathrm{C}_{8} \mathrm{H}_{17}-\mathrm{O}-\mathrm{OCO}-\mathrm{O}-\mathrm{OCO}-\mathrm{O}-\mathrm{NO}_{2}$ \\
\hline $\mathrm{DB} 6 \mathrm{NO}_{2}$ & $\mathrm{C}_{6} \mathrm{H}_{15}-\mathrm{O}-\mathrm{OCO}-\mathrm{O}-\mathrm{OCO}-\mathrm{O}-\mathrm{NO}_{2}$ \\
\hline $\mathrm{DB} 7$ & $\mathrm{C}_{7} \mathrm{H}_{15}-\mathrm{O}-\mathrm{OCO}-\mathrm{O}-\mathrm{OCO}-\mathrm{O}-\mathrm{CN}$ \\
\hline
\end{tabular}

Changing the DB5 compound, textural similarities allow us to confirm for the DB6-C5 stilbene and the DB7-C5 stilbene systems the existence of such a crenelated $\mathrm{S}_{\mathrm{A}}$ phase, but still in a very narrow range of temperature (Fig. 1). Unfortunately, experimental resolution prevented us from giving the topology of the two possible triple points $\left(\mathrm{S}_{\mathrm{A}_{1}}-\mathrm{S}_{\tilde{A}_{\mathrm{A}}}-\mathrm{S}_{\mathrm{A}_{2}} ; \mathrm{S}_{\mathrm{A}^{-}}-\mathrm{S}_{\mathrm{A}_{\mathrm{cre}}}-\mathrm{S}_{\mathrm{A}_{2}}\right)$ recently predicted in the frame of a mean field theory by L. G. Benguigui [8].

\section{$\mathbf{S}_{\mathrm{A}_{1}}-\mathbf{S}_{\tilde{\mathbf{C}}}-\mathbf{S}_{\tilde{\mathrm{A}}}$ sequence}

The occurrence of a $S_{\tilde{A}}$ antiphase in a pure compound has been clearly shown for the $\mathrm{DB} 7 \mathrm{NO}_{2}$ compound by $\mathrm{X}$-ray analysis [9].

In addition we know that the polymorphism is largely modified for the higher homologue $\left(\mathrm{DB} 8 \mathrm{NO}_{2}\right)$ : the high temperature phase is of the $\mathrm{S}_{\mathrm{A}_{d}}$ type (instead of $\mathrm{S}_{\mathrm{A}_{1}}$ ) and the 2D fluid smectic is assigned as $\mathrm{S}_{\tilde{\mathrm{C}}}$ [3]. The X-ray study of several mixtures of both homologues is consistent with 


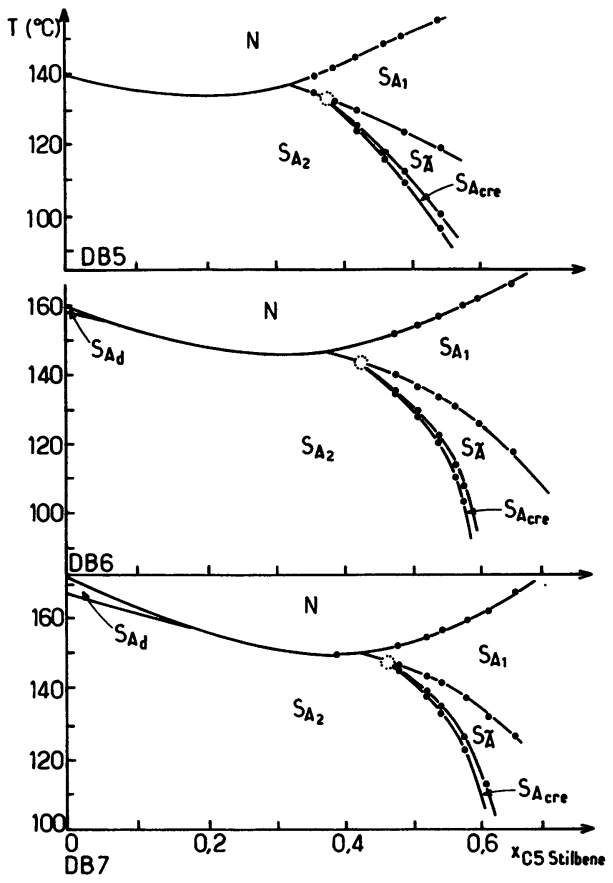

Fig. 1. $-(x, T)$ phase diagrams $(P=1 \mathrm{~atm})$ for the systems : DB5 (left) - C5 stilbene (right); DB6 (left) C5 stilbene (right); DB7 (left) - C5 stilbene (right).
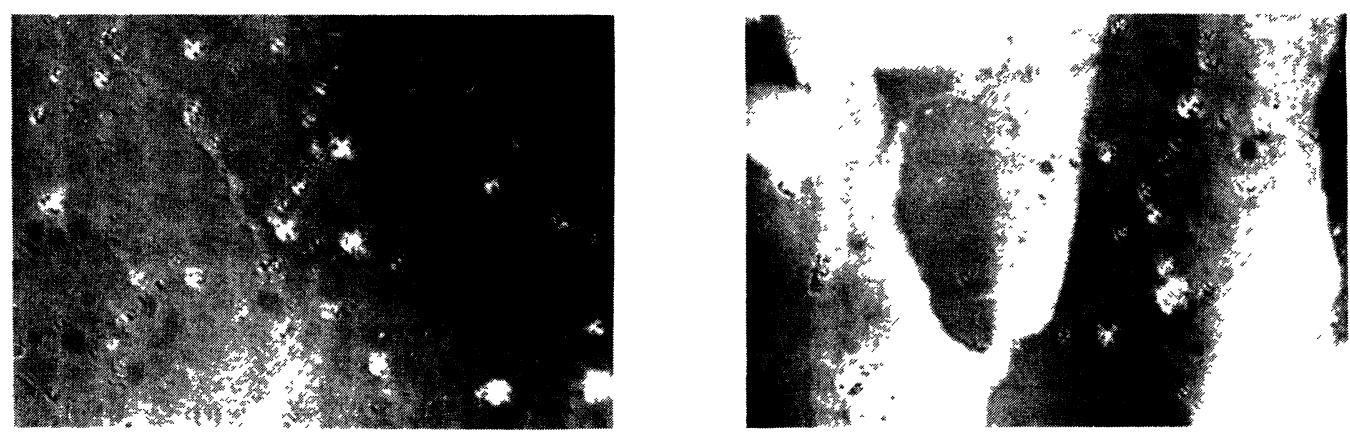

a)

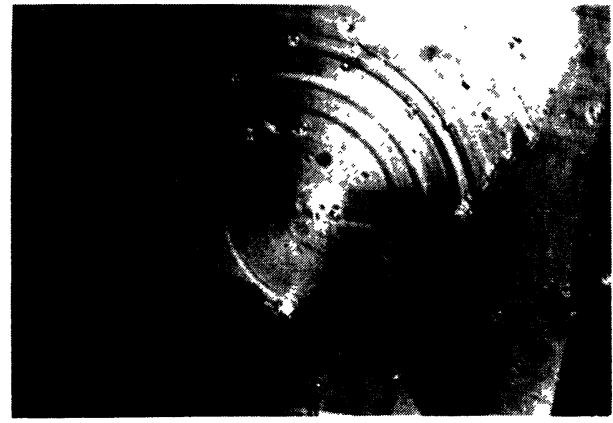

b)

c)

Fig. 2. - Microphotographs taken at different temperatures for the DB7 $\mathrm{NO}_{2}-0.08 \mathrm{DB} 8 \mathrm{NO}_{2}$ mixture : (a) $T=95^{\circ} \mathrm{C}, \mathrm{S}_{\mathrm{A}_{1}}$; (b) $T=92^{\circ} \mathrm{C}, \mathrm{S}_{\tilde{\mathrm{C}}}$; (c) $T=90^{\circ} \mathrm{C}, \mathrm{S}_{\tilde{\mathrm{A}}}$. 
a $\mathrm{S}_{\tilde{\mathrm{A}}}$ being maintained up to a $x=0.2$ molar fraction of $\mathrm{DB} 8 \mathrm{NO}_{2}$ [1]. Regarding the microscopic investigation of these binary mixtures, it is worth noting that the polygonal texture of the $S_{\tilde{\mathbf{C}}}$ appears much less birefringent when it arises from a $S_{A_{1}}$ that when it follows the $S_{A_{d}}$. Even in these situations where the $S_{\widetilde{\mathbf{c}}}$ texture has disrupted the homeotropy, the improvement in our experience in the microscopic observation of free droplets permit the detection of characteristic defects of the $S_{\tilde{A}}$ phase when it exists. The occurrence (or the vanishing) of these defects upon cooling (or heating) at a given temperature over the $S_{\widetilde{C}}$ texture give evidence for a reversible $\mathrm{S}_{\widetilde{\mathrm{C}}} \underset{T \Lambda}{\stackrel{T \Lambda}{\rightleftarrows}} S_{\widetilde{\mathrm{A}}}$ transition (Fig. 2). This essential criterion has been used to reveal a line for the $\mathrm{S}_{\widetilde{\mathrm{C}}}-\mathrm{S}_{\tilde{\mathrm{A}}}$ transition temperatures in the binary diagrams of homologous compounds of the $\mathrm{DB}_{n} \mathrm{NO}_{2}$ series (Fig. 3). Another connected result is that the $\mathrm{S}_{\tilde{\mathrm{C}}}$ still exists in a narrowing range of temperature for the pure $\mathrm{DB} 7 \mathrm{NO}_{2}\left(\right.$ over $2^{\circ} \mathrm{C}$ ) and for the pure $\mathrm{DB} 6 \mathrm{NO}_{2}\left(\right.$ over $0.2^{\circ} \mathrm{C}$ ).

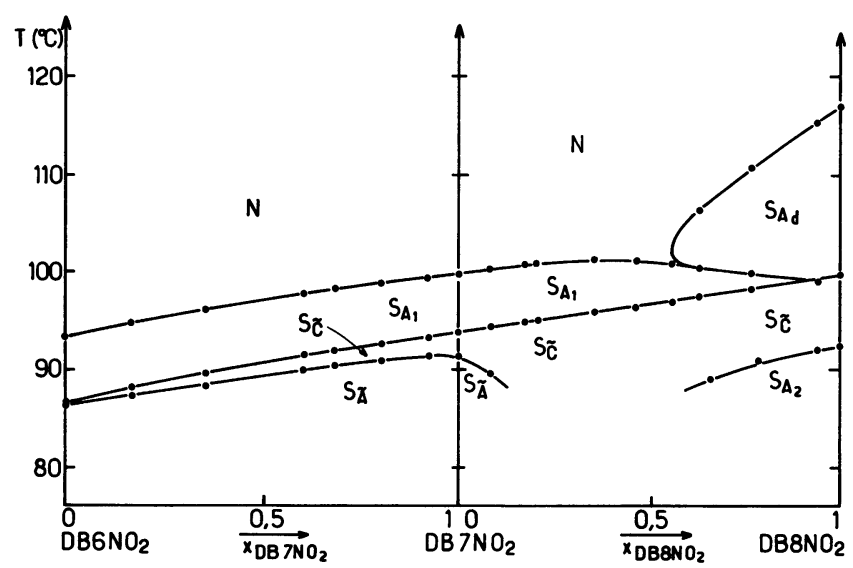

Fig. 3. - Successive $(x, T)$ phase diagrams $(P=1 \mathrm{~atm})$ for the systems : DB6 $\mathrm{NO}_{2}-\mathrm{DB} 7 \mathrm{NO}_{2}$ and DB7 $\mathrm{NO}_{2}$ - DB8 $\mathrm{NO}_{2}$.

\section{$\mathbf{S}_{\mathrm{A}_{1}}-\mathbf{S}_{\tilde{\mathrm{A}}}-\mathbf{S}_{\widetilde{\mathrm{C}}}-\mathbf{S}_{\mathrm{A}_{\text {cre }}}-\mathbf{S}_{\mathrm{A}_{2}}$ sequence.}

Keeping in mind previous results, we have considered mixtures of $\mathrm{DB} 7 \mathrm{NO}_{2}$ with small amounts of DB7 in order to stabilize a $\mathrm{S}_{\mathrm{A}_{2}}$ phase at lower temperatures. By analogy with our microscopic criteria reported here we have detected the following changes with decreasing temperature from the nematic phase : first, the homeotropic aspect of the $S_{A_{1}}$ phase (Fig. 4a), second the $S_{\tilde{C}}$ textures (Fig. 4b) in which appear at a given temperature the lines of defects characteristic of the $S_{\tilde{A}}$ phase (Fig. 4c), then the textures of the $S_{\mathrm{A}_{\mathrm{cre}}}$ develop (Fig. 4d) and at last the homeotropic alignment takes place again in the $S_{A_{2}}$ phase (Fig. 4e). The part of the diagram corresponding to this polymorphism is depicted in figure 5 . As mentioned earlier, we stress that the narrow temperature interval of the $S_{A_{\text {cre }}}$ phase appears to be a necessary step between $S_{\tilde{A}}\left(\right.$ or $S_{\tilde{C} \text { ? }}$ ) and the $S_{A_{2}}$ phase. To conclude, this extension of the sequences of $2 \mathrm{D}$ fluid smectics between $S_{\mathrm{A}_{1}}$ and $\mathrm{S}_{\mathrm{A}_{2}}$ phases will certainly be difficult to confirm by high resolution $\mathrm{X}$-ray and calorimetric experiments considering the studies performed on $\mathrm{DB} 7 \mathrm{NO}_{2}[10,11]$. 


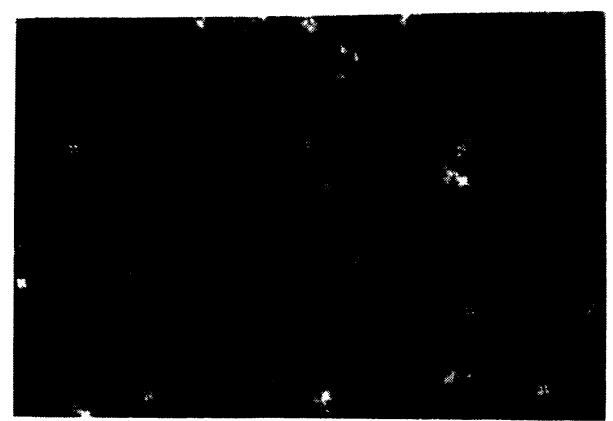

a)

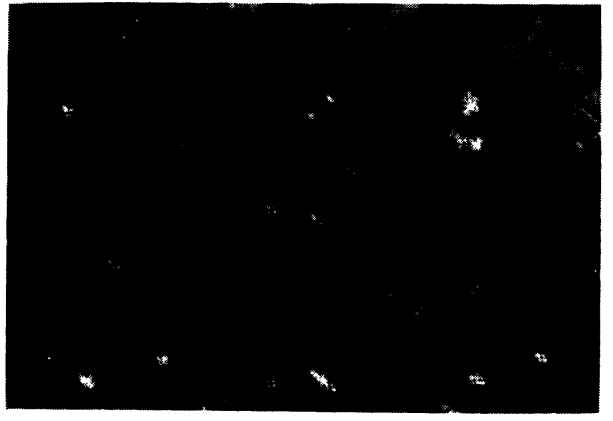

b)

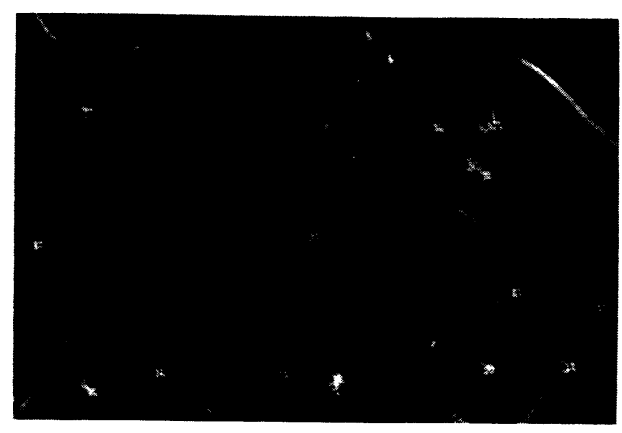

d)

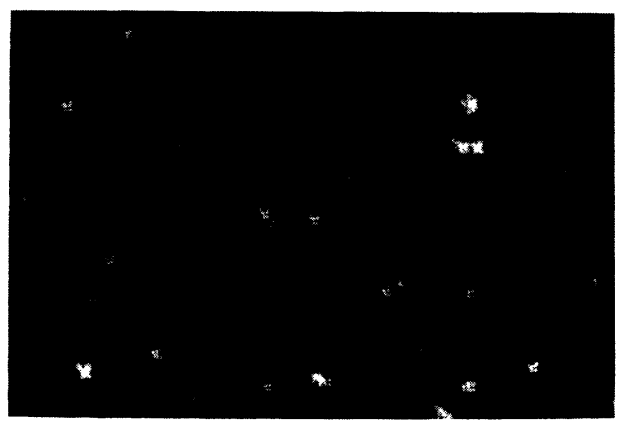

e)

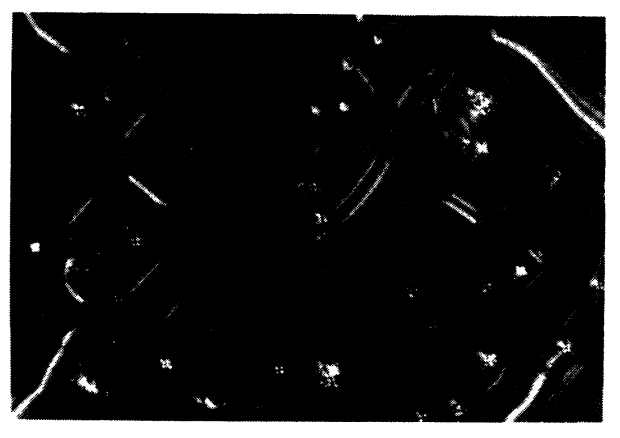

c)

Fig. 4. - Series of microphotographs taken at different temperatures for the DB7 $\mathrm{NO}_{2}-0.09 \mathrm{DB} 7 \mathrm{mix}-$ ture : (a) $T=103.5^{\circ} \mathrm{C}, \mathrm{S}_{\mathrm{A}_{1}}$; (b) $T=100.5^{\circ} \mathrm{C}, \mathrm{S}_{\tilde{\mathrm{C}}}$; (c) $T=96.5^{\circ} \mathrm{C}, \mathrm{S}_{\tilde{\mathrm{A}}}$; (d) $T=94.5^{\circ} \mathrm{C}, \mathrm{S}_{\mathrm{A}_{\text {cre }}}$; (e) $T=94.0^{\circ} \mathrm{C}, \mathrm{S}_{\mathrm{A}_{2}}$. 


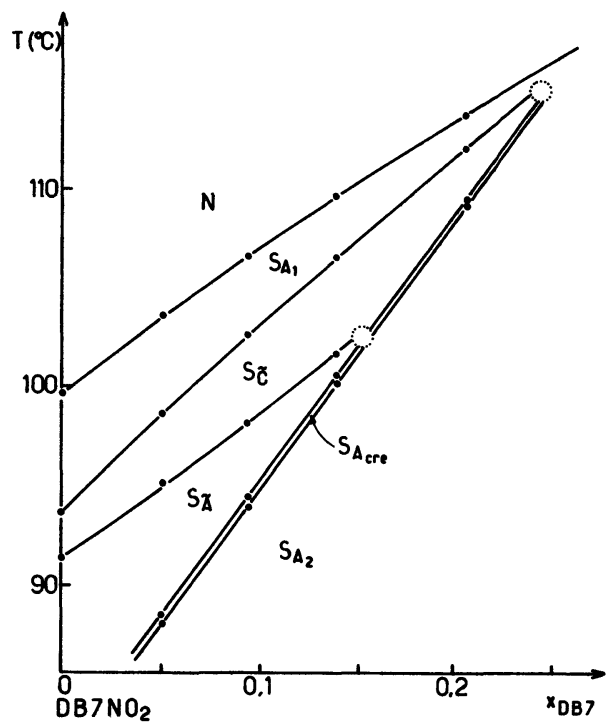

Fig. 5. - Part of the phase diagram for the system DB7 $\mathrm{NO}_{2}$ (left) - DB7 (right), $0<x_{\mathrm{DB} 7}<0.25$.

\section{References}

[1] Hardouin, F., Levelut, A. M., Achard, M. F., Sigaud, G., J. Chim. Phys. 80 (1983) 53 and references therein.

[2] Gray, G. W., Goodby, J. W. G., Smectic Liquid Crystals (1984) 143-148 (Leonard Hill Ed., Glasgow and London; Heyden and Son Inc., Philadelphia, USA).

[3] Hardouin, F., Nguyen Huu Tinh, Achard, M. F., Levelut, A. M., J. Physique Lett. 43 (1982) L-327.

[4] Nguyen Huu Tinh, Hardouin, F., Destrade, C., J. Physique 43 (1982) 1127.

[5] Sigaud, G., Hardouin, F., Achard, M. F., Levelut, A. M., J. Physique 42 (1981) 107.

[6] LeVelut, A. M., J. Physique Lett. 45 (1984) L-603.

[7] Sigaud, G., Hardouin, F., Achard, M. F., Phys. Rev. A 31 (1985) 547.

[8] Benguigui, L. G., to be published.

[9] Hardouin, F., Sigaud, G., Nguyen HuU Tinh. Achard, M. F., J. Physique Lett. 42 (1981) L-63.

[10] Safinya, C. R., Chiang, L. Y., Bull. Am. Phys. Soc. 28 (1983) 333.

[11] Huang, C. C., Lien, S. C., Dumrongrattana, S., Chiang, L. Y., Phys. Rev. A 30 (1984) 965. 